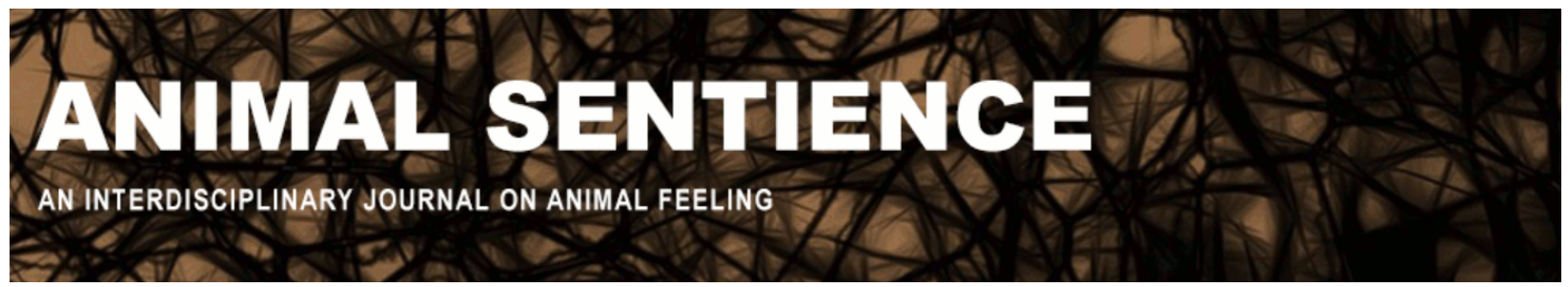

Vonk, Jennifer (2019) Octopi-ing a unique niche in comparative psychology. Animal Sentience 26(6)

DOI: $10.51291 / 2377-7478.1474$

Date of submission: 2019-06-01

Date of acceptance: 2019-06-06

(c) (†)

This article has appeared in the journal Animal

Sentience, a peer-reviewed journal on animal

cognition and feeling. It has been made open access,

free for all, by WellBeing International and deposited

in the WBI Studies Repository. For more information,

please contact

wbisr-info@wellbeingintl.org.

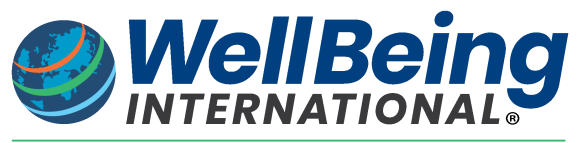

SOLUTIONS FOR PEOPLE, ANIMALS AND ENVIRONMENT 


\title{
Octopi-ing a unique niche in comparative psychology
}

\author{
Commentary on Mather on Octopus Mind
}

\author{
Jennifer Vonk \\ Department of Psychology \\ Oakland University
}

\begin{abstract}
Mather's work has been fundamental in informing scientists of the relatively mysterious behavior and cognition of an understudied group of animals - the cephalopods. This work helps to fill a gap in the comparative literature that has historically sought evidence for complex behavior only in species that are closely related to humans or share important ecological features such as social complexity.
\end{abstract}

\begin{abstract}
Jennifer Vonk, Professor of Psychology, Oakland University, studies cognition in a wide range of species. She investigates cognition from evolutionary and animal welfare perspectives. Website
\end{abstract}

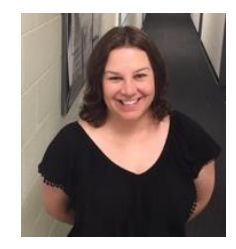

Mather's (2019) research is profoundly important to the field of comparative psychology, as the octopus exhibits such a unique morphology and exists within a niche where few species are studied, especially with regard to cognition. Comparative psychologists are only beginning to value studies of diverse species and emerge from the shadow of their laboratory history focusing on a small number of species such as rats, pigeons and macaques (Vonk \& Shackelford, 2012).

In this commentary, I do not wish to engage with arguments regarding the extent to which the octopus has a mind or consciousness. Rather, I would like to focus on the value of understanding how such a species does represent its world given its uniqueness. Humans are better equipped to translate the behavior of closely related species, such as nonhuman primates, into a representation of their cognition. Even with distantly related species such as rodents and corvids, we share terrestrial and social environments, and with aquatic mammals, such as cetaceans, we share some homologies; e.g., complex vocal communication and parental investment. As Mather (2019) makes clear, the octopus, in contrast, is so foreign in its decentralized nervous system and ecology that a better understanding of its abilities could elucidate how similar behaviors may evolve in response to different selection pressures. The octopus also serves as a reminder that selection creates different solutions to similar problems in variable environments.

The study of such organisms poses myriad challenges. Not the least of these is the fact that cephalopods may prioritize chemical modalities and utilize vision in a way that is very different from how humans perceive the world. The need to coordinate so many appendages simultaneously has likely sculpted their cognition in ways that humans cannot fathom, as Mather identifies. It is a testament to the ingenuity of researchers like Mather that so many cephalopod 
traits have been uncovered, even if the larger scientific community (as evidenced by other commentaries) remains uncertain as to how the data should be interpreted.

Researchers tend to be myopic with regard to how "advanced" cognition can evolve. Historically, we have focused on re-tracing our own evolutionary history within the primate order, which makes a good degree of sense, of course, as examining cognition in extant species within the same lineage may help indicate when the capacity emerged. However, this strategy neglects the possibility of convergent evolution. More recently, humans have identified with the social cognition of highly social animals like canids, cetaceans and corvids, and have attributed primatelike cognition to corvids.

In contrast, when attempting to understand basic learning processes through invasive techniques, we have commonly exploited more distantly related species, such as laboratory rats (although we have certainly exposed nonhuman primates to their share of invasive research). Backlash against such practices typically focuses on the purported intelligence of such species and their capacity to feel emotions. It is thus unsurprising that researchers focus on such aspects when attempting to effect change in animal welfare practices. However, as Gutfreund (2019) points out, animals need not be attributed minds to be of scientific interest, and scientists should appreciate how various species have evolved to adapt to their environments in complex and impressive ways. Schwartz (2019) similarly reminds us of the important lesson from Pinker's (1994) elephant biologist example; we should not judge animal minds by human standards.

Our fascination with the octopus and its amazing problem-solving abilities will ideally serve as a reminder that there are multiple routes to the same outcome. Thus, we should be open to observing "advanced cognition" in many species, not just the ones we find the most relatable to ourselves. This should have implications not only for our treatment of other species but for how we approach our science. Studying non-social species is essential to properly assessing the social intelligence hypothesis (Eaton et al., 2017). For too long, we have allowed assumptions about what sorts of animals should be able to perform certain tasks to dictate the focus of our science rather than investigating how various species do approach the problems they face. When closely related species, such as chimpanzees, behave as we expect humans to do, we are all too ready to assume similar underlying mechanisms, even when the corpus of data may not support such assumptions (Vonk, in press). When we identify complex behavior in more distant and less obviously "charismatic" species, such as fish and insects, we are more likely to discount reports of impressive cognitive feats and eschew the experimental paradigms giving rise to such reports (e.g., Vonk, 2019). For example, reports of emotion states in bees (Baracchi, Lihoreau, \& Giurfa, 2017) and mirror-self recognition in fish (Kohda et al., 2019) have come under fire, but less compelling evidence for the same behaviors in primates and other charismatic species, like dolphins, is more readily embraced (e.g., Delfour, 2001).

Mather astutely argues for the importance of testing species in their natural environments, as well as in more carefully controlled laboratory conditions. By testing species that have adapted to a multitude of environments, we are better able to understand how cognition evolved. For example, if we find that non-social animals are able to learn from watching the behaviors of others (even non-conspecifics), we will no longer assume that social learning can emerge only as a function of living in large social groups, as has been demonstrated by Wilkinson and her groundbreaking work with reptiles (Kis, Huber, \& Wilkinson, 2015), and at least one research group working with the common octopus (Fiorito \& Scotto, 1992, although Mather notes 
this has not been replicated). Like Wilkinson, Mather has opened a window into an unknown mind. Insights from this breakthrough will be appreciated only when we can open our own minds to possibilities we may not yet have imagined. Work with cephalopods will challenge our assumptions about the role of sociality, human-like brain structures and long lifespans in shaping complex cognition.

\section{References}

Baracchi, D., Lihoreau, M., \& Giurfa, M. (2017). Do insects have emotions? Some insights from bumble bees. Frontiers in Behavioral Neuroscience, 11, 4.

Delfour, F., \& Marten, K. (2001). Mirror image processing in three marine mammal species: Killer whales, (Orchinus orca) false killer whales (Pseudorca crassidens) and California sea lions (Zalophus californianus). Behavioural Processes, 53(3), 181-190.

Eaton, T., Hutton, R., Leete, J., Lieb, J., Robeson, A., \& Vonk, J. (2018). Bottoms-up: Rejecting top-down human-centered approaches in comparative psychology. International Journal of Comparative Psychology, 31.

Gutfreund, Y. (2019). Who needs a mind when you have thousands of fingers? Animal Sentience 26(3).

Kis, A., Huber, L., \& Wilkinson, A. (2015). Social learning by imitation in a reptile (pogona vitticeps). Animal Cognition, 18, 325-331.

Kohda, M., Hotta, T., Takeyama, T., Awata, S., Tanaka, H., Asai, J-y., \& Jordan, A. L. (2019). If a fish can pass the mark test, what are the implications for consciousness and self-awareness testing in animals? PLoS Biology, 17(2), e3000021.

Mather, J. (2019). What is in an octopus's mind? Animal Sentience 26(1).

Pinker, S. (1994). The Language Instinct. Harper Perennial: New York.

Schwartz, B.L. (2019). A community of minds. Animal Sentience 26(4).

Vonk, J. (2019). A fish eye view of the mirror test. Learning and Behavior.

Vonk, J. (in press). A stalemate in theorizing about mindreading in nonhuman animals: A bottom-up approach. In F. Grasso, J. E. Burgos, Ó. García-Leal, \& R. Akram (Eds.), The MindReading Brains. New York, NY: Springer Publishers.

Vonk, J., \& Shackelford, T.K. (2012). Comparative evolutionary psychology: A united discipline for the study of evolved traits. In J. Vonk \& T. Shackelford (Eds.), Oxford Handbook of Comparative Evolutionary Psychology (pp. 547-560). New York, NY: Oxford University Press. 